\title{
From the Editors' Desk: Valuing Health and Primary Care
}

\author{
Malathi Srinivasan, $M D^{7}$ and Mitchell D. Feldman, MD MPhil \\ 'Division of General Internal Medicine, Department of Medicine, University of California Davis, Sacramento, CA, USA; ${ }^{2}$ Division of General \\ Internal Medicine, Department of Medicine, University of California, San Francisco, San Francisco, CA, USA.
}

J Gen Intern Med 26(9):947

DOI: $10.1007 / \mathrm{s} 11606-011-1800-\mathrm{Z}$

(c) Society of General Internal Medicine 2011

$I^{n}$ June 2011, James Verone walked into a bank in North Carolina and attempted to rob it for a single dollar. Three years previously, he had been laid off from his 17-year job as a Coca-Cola deliveryman and, unable to find permanent alternative employment, had depleted his life savings. Unlike most bank robbers in this predicament, his goal was not pecuniary, though he certainly could use more money. Instead, his objective was to be apprehended and eventually imprisoned for robbery in order to obtain free health care from within the prison system. Unarmed, he was taken into custody. Sadly, Mr. Verone felt that the prison health care system was his best option for having access to medical care for his chronic medical conditions.

Mr. Verone's actions, while extreme, highlight the continuing problem of access to health care faced by over 50 million people in the US. The 2010 Patient Protection and Affordable Care Act health reform bill is poised to decrease that number dramatically, by increasing health care access through taxes, offsets, and negotiated deals - for an estimated $\$ 900 B$ invested over 10 years. Among other measures, the PPACA enacted provisions to mandate most legal US residents to buy or continue health insurance (through subsidies, health insurance exchanges, penalties and employer mandates), and prohibits discrimination by insurance companies based on pre-existing conditions. Additionally, the provisions of the 2009 American Recovery and Reinvestment Act (ARRA) provided \$90B to states to strengthen Medicaid, \$2B for community health care centers, and more.

These progressive acts of legislation have an underlying assumption-that increased demand for medical care can be accommodated by our current system of medical care. However, as most patients know, primary care practices are full. The 350,000 US primary care physicians are unlikely to have the capacity to provide care for the PPACA-subsidized newly insured. The AAMC estimates a 150,000 physician shortfall within 15 years.

Published online July 23, 2011
In this issue of JGIM, several papers explore the value of primary care access and patient empowerment. DeVoe addresses the need for insured patients to obtain access to a usual source of care. In her cohort of 62,000 Medical Expenditure Panel Survey (MEPS) adults, insured patients without a usual source of care were significantly more likely to have problems obtaining primary care. Using a nationally representative sample of 1,000 US primary care physicians, Carrier studied the relationship between quality of care delivered and socio-economic characteristics of their Medicare patients. Her findings of a significant but inconsistent relationship between lower quality of care and lower income and education, black race and Medicaid eligibility are important to consider as we re-consider methods to provide equitable care using ARRA stimulus funds.

In addition to measures used to improve access to care, innovative solutions must be found to help patients maintain or improve their health. For instance, in this issue of JGIM, Hill-Briggs and colleagues randomized 56 urban AfricanAmericans with poorly controlled diabetes and hypercholesterolemia to an intensive and condensed literacy-adapted selfmanagement course. Her patients underwent health problemsolving training. While all patients had an improvement in knowledge, at 3 months the intensive education group decreased their HbAlc by $0.71 \%$.

James Verone took extreme and unusual measures to gain access to medical care. While access to primary care is a necessary first step to improve health outcomes, access alone will not ensure high quality medical care. As we confront the urgent need for health care reform in the US, we must consider new models to engage our patients in their own health care for chronic disease management-keeping in mind current variations in health care outcomes across education, income and race.

Corresponding Author: Malathi Srinivasan, MD; Division of General Internal Medicine, Department of Medicine, University of California Davis, 4150 V. Street, Suite 2400, Sacramento, CA 95817 , USA (e-mail: malathi@ucdavis.edu). 